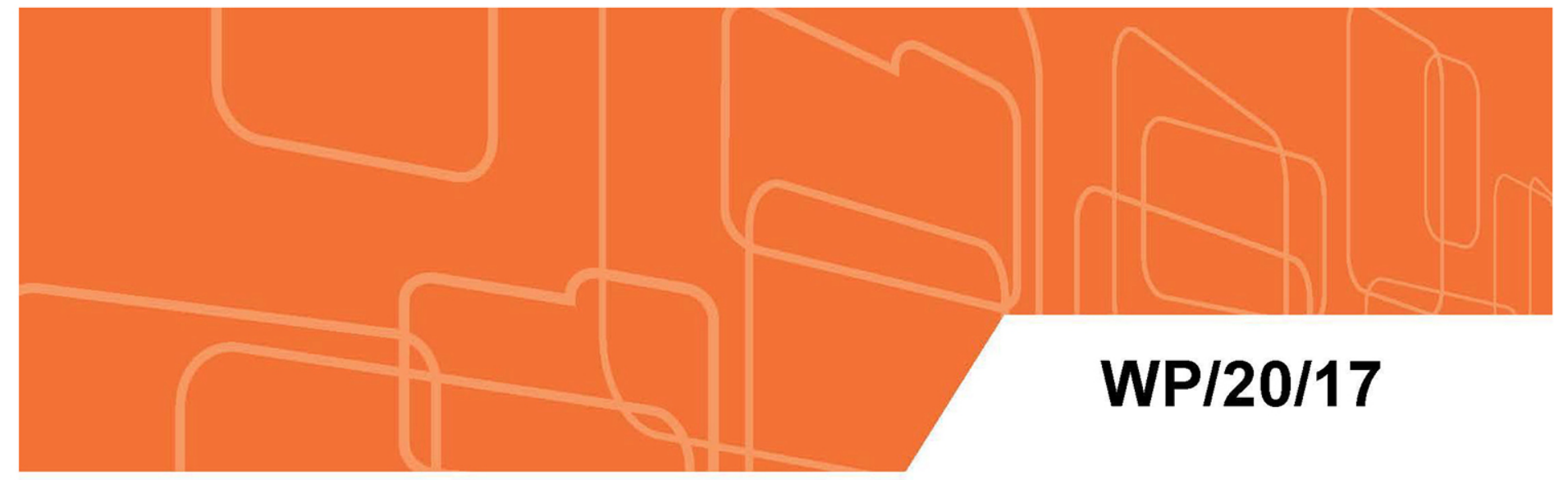

IMF Working Paper

\title{
How Big are Fiscal Multipliers in Latin America?
}

\author{
Jorge E. Restrepo
}

IMF Working Papers describe research in progress by the author(s) and are publis hed to elicit comments and to encourage debate. The views expressed in IMF Working Papers are those of the author(s) and do not necessarily represent the views of the IMF, its Executive Board, or IMF management. 


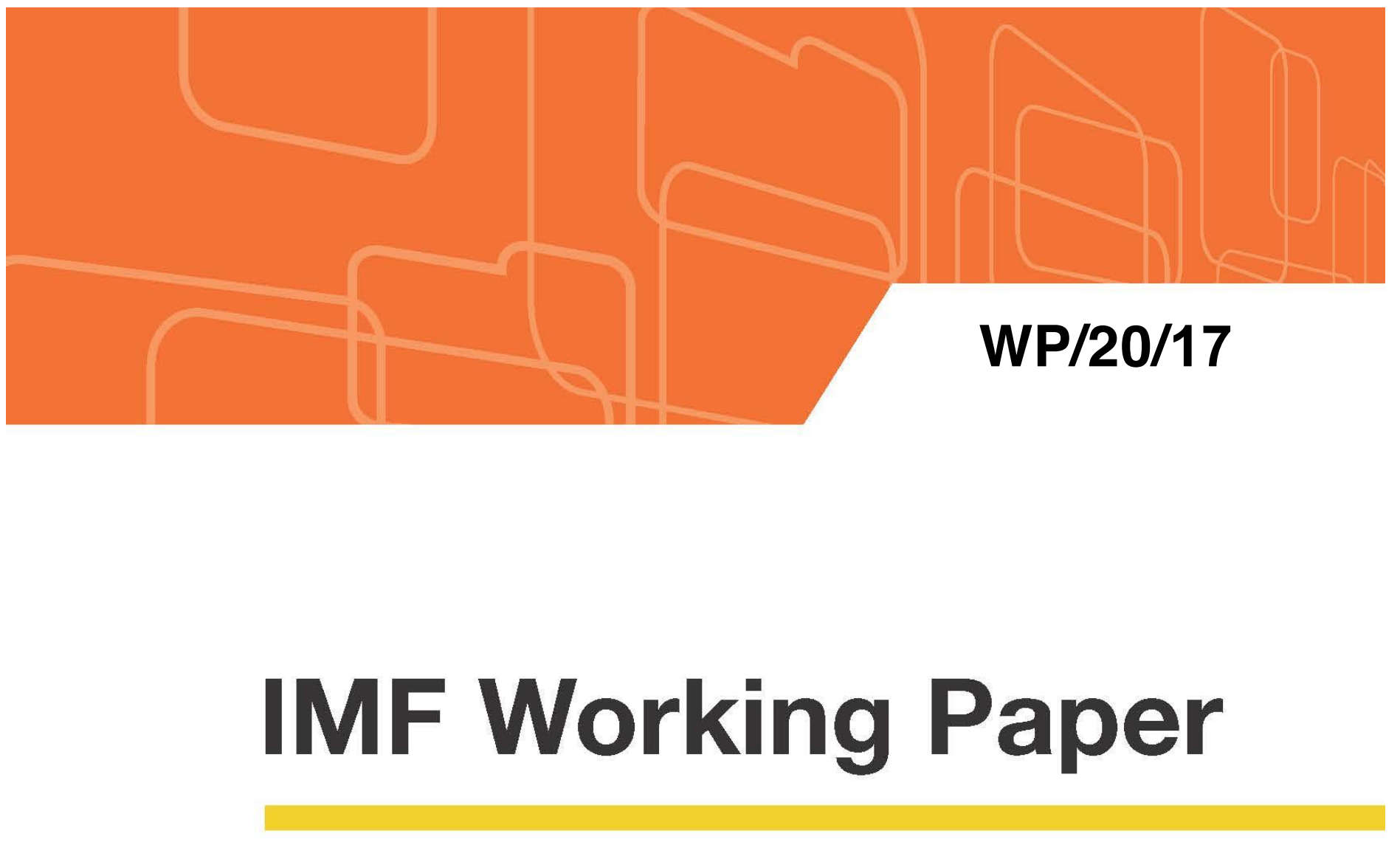

\title{
How Big are Fiscal Multipliers in Latin America?
}

\author{
Jorge E. Restrepo
}

IMF Working Papers describe re search in progress by the author(s) and are publis hed to elicit comments and to encourage debate. The views expressed in IMF Working Papers are those of the author(s) and do not necessarily represent the views of the IMF, its Executive Board, or IMF management. 


\title{
IMF Working Paper
}

Western Hemisphere Department

\section{How Big are Fiscal Multiplie rs in Latin Ame rica?}

Prepared by Jorge E. Restrepo

Authorized for distribution by Jorge Roldos

January 2020

\section{IMF Working Papers des cribe research in progress by the author(s) and are published to} elicit comments and to e ncourage debate. The views expressed in IMF Working Papers are those of the author(s) and do not necessarily represent the views of the IMF, its Executive Board, or IMF management.

\begin{abstract}
This paper uses the strategy and data of Blanchard and Perotti (BP) to identify fiscal shocks and estimate fiscal multipliers for the United States. With these results, it computes the cumulative multiplier of Ramey and Zubairy (2018), now common in the literature. It finds that, contrary to the peak and through multipliers reported by BP, the cumulative tax multiplier is much larger than the cumulative spending one. Hence, the conclusions depend on the definition of multiplier. This methodology is also used to estimate the effects of fiscal shocks on economic activity in eight Latin American countries. The results suggest that the fiscal multipliers vary significantly across countries, and in some cases multipliers are larger than previously estimated.
\end{abstract}

JEL Classification Numbers: E6, E62

Keywords: Macroeconomic Policy, Stabilization, Fiscal Policy, Multipliers

Author's E-Mail Address: Jrestrepo@imf.org 


\section{Contents}

I. INTRODUCTION

\section{BLANCHARD AND PEROTTI'S (BP'S) APPROACH FOR THE UNITED} STATES

III. MULTIPLIERS IN LAC COUNTRIES

IV. SUMMARY AND CONCLUSIONS

\section{FIGURES}

1. US: responses to a spending shock: deterministic trends

2. US: responses to a tax shock: deterministic trends

3. US: responses to a spending shock: stochastic trends

4: US: responses to a tax shock: stochastic trends

5. Brazil: responses to a spending and tax shocks

6. Chile: responses to a spending and tax shocks $\underline{10}$

7. Colombia: responses to a spending and tax shocks

8. Dominican Republic: responses to a spending and tax shocks

9. Mexico: responses to a spending and tax shocks

10. Paraguay: responses to a spending and tax shocks

11. Peru: responses to a spending and tax shocks

12. Uruguay: responses to a spending and tax shocks

TABLES

1. Data, Sources, and Coverage 11

2. Dickey-Fuller Tests $\underline{12}$

3. Fiscal Multipliers $\underline{13}$

References $\underline{22}$ 


\section{INTRODUCTION ${ }^{1}$}

Fiscal deficits and public debt have risen significantly in many economies in Latin America and the Caribbean (LAC) in recent years. This is the result of a fiscal stimulus implemented in 2008-09 that was not fully reversed and a fall in revenues led by a decline in commodity prices and economic activity since 2013 . As a result, LAC countries are now implementing fiscal consolidation measures and will continue to do so in the coming years (see October 2019 Regional Economic Outlook: Western Hemisphere). In this context, it is key to have a good understanding of the economic effects of these measures.

To contribute to this discussion, this paper uses the strategy of Blanchard and Perotti (2002) (BP) to identify fiscal shocks and estimate fiscal multipliers for eight LAC economies. BP's strategy uses time-series to econometrically identify movements in government spending and tax revenues that are exogenous to the economic cycle. As explained in Sims (1980), the econometric approach imposes as few restrictions as possible on the relations among the endogenous variables and allows the data to speak for itself as much as possible.

Section II discusses BP's approach in detail and shows some interesting results that come out from their estimation for the United States. Section III shows the results country by country for eight LAC economies. Section IV concludes and provides some policy recommendations.

\section{BLANCHARD AND PEROTTI's (BP'S) APPROACH FOR THE UNITED STATES}

BP's strategy consists of unveiling an unobservable structural model starting from a reducedform vector autoregression $X_{t}=E(L, q) X_{t-1}+e_{t}$, where $X_{t}=\left[S_{t}, T_{t}, Y_{t}\right]^{\prime}$ includes the logarithm of quarterly per capita real spending (government consumption and investment), tax revenue (minus transfers and interest payments), and GDP, respectively, and $e_{t}$ is the vector of estimated residuals. ${ }^{2}$ To obtain the structural model and shocks, it is first assumed that there is a linear relationship between the reduced-form estimated residuals $e_{t}$ and the structural uncorrelated shocks $\boldsymbol{u}_{\boldsymbol{t}}$ :

$$
\begin{aligned}
& e_{t}^{s}=b_{1} e_{t}^{y}+b_{2} u_{t}^{T}+u_{t}^{s} \\
& e_{t}^{T}=a_{1} e_{t}^{y}+a_{2} u_{t}^{s}+u_{t}^{T} \\
& e_{t}^{y}=c_{2} e_{t}^{s}+c_{1} e_{t}^{T}+u_{t}^{y} .
\end{aligned}
$$

In Blanchard and Perotti's SVAR, it is initially assumed that unexpected movements in spending $\left(\boldsymbol{e}_{\boldsymbol{t}}^{\boldsymbol{S}}\right)$ are due to GDP forecast errors $\left(\boldsymbol{b}_{1} \boldsymbol{e}_{\boldsymbol{t}}^{\boldsymbol{y}}\right)$, structural shocks to taxes $\left(\boldsymbol{b}_{\mathbf{2}} \boldsymbol{u}_{\boldsymbol{t}}^{\boldsymbol{T}}\right)$, and structural shocks to government spending $\left(\boldsymbol{u}_{t}^{\boldsymbol{S}}\right)$. Forecast errors in taxes $\left(\boldsymbol{e}_{\boldsymbol{t}}^{\boldsymbol{T}}\right)$ are due to surprise movements in GDP $\left(\boldsymbol{a}_{1} \boldsymbol{e}_{t}^{\boldsymbol{y}}\right)$, structural shocks to spending $\left(\boldsymbol{a}_{2} \boldsymbol{u}_{\boldsymbol{t}}^{\boldsymbol{S}}\right)$, and structural

\footnotetext{
${ }^{1}$ I thank comments by Jaime Guajardo and members of the country teams: Pelin Berkmen, Julia Faltermeier, Pedro Rodriguez, Tobias Roy, and Christian Saborowski (WHD); Jiro Honda, Babacar Sarr, and Hiroaki Miyamoto (FAD), as well as excellent res earch assistance by Genevieve Lindow.

${ }^{2}$ Where the $\boldsymbol{E}$ s are the coefficients obtained es timating the reduced-form.
} 
shocks to taxes $\left(\boldsymbol{u}_{t}^{\boldsymbol{T}}\right)$. Finally, GDP forecast errors $\left(\boldsymbol{e}_{t}^{\boldsymbol{y}}\right)$ are due to surprise movements in spending $\left(\boldsymbol{c}_{\mathbf{2}} \boldsymbol{e}_{\boldsymbol{t}}^{\boldsymbol{S}}\right)$, surprise movements in taxes $\left(\boldsymbol{c}_{\mathbf{1}} \boldsymbol{e}_{\boldsymbol{t}}^{\boldsymbol{T}}\right)$, and structural shocks to GDP $\left(\boldsymbol{u}_{\boldsymbol{t}}^{\boldsymbol{y}}\right)$.

Which in matrix form is expressed as:

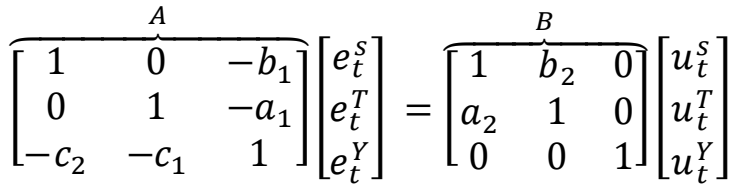

pre-multiplying this expression by the inverse of A, yields $\boldsymbol{e}_{\boldsymbol{t}}=\boldsymbol{A}^{\mathbf{- 1}} \boldsymbol{B} \boldsymbol{u}_{\boldsymbol{t}}$ :

$\left[\begin{array}{l}e_{t}^{S} \\ e_{t}^{T} \\ e_{t}^{Y}\end{array}\right]=\overbrace{\left[\begin{array}{ccc}1 & 0 & -b_{1} \\ 0 & 1 & -a_{1} \\ -c_{2} & -c_{1} & 1\end{array}\right]}^{A} \overbrace{}^{-1} \overbrace{\left.\begin{array}{ccc}1 & b_{2} & 0 \\ a_{2} & 1 & 0 \\ 0 & 0 & 1\end{array}\right]}^{B}\left[\begin{array}{l}u_{t}^{S} \\ u_{t}^{T} \\ u_{t}^{Y}\end{array}\right]$

Let call $\boldsymbol{A}^{-1} \boldsymbol{B}=\boldsymbol{F}$ then, $\boldsymbol{e}_{\boldsymbol{t}}=\boldsymbol{F} \boldsymbol{u}_{\boldsymbol{t}} . \boldsymbol{F}$ is the matrix used to obtain the structural model and to build the impulse responses. With $\boldsymbol{F}$, one can go from the reduced form, $\boldsymbol{X}_{\boldsymbol{t}}=\boldsymbol{E}_{\mathbf{1}} \boldsymbol{X}_{\boldsymbol{t}-\mathbf{1}}+\boldsymbol{e}_{\boldsymbol{t}}$, to the structural VAR, $\boldsymbol{F}^{-1} \boldsymbol{X}_{\boldsymbol{t}}=\boldsymbol{G}_{\mathbf{1}} \boldsymbol{X}_{\boldsymbol{t}-\mathbf{1}}+\boldsymbol{u}_{\boldsymbol{t}}$, and vice versa. The relation among the reducedform innovations and the structural shocks imply contemporaneous relations among the endogenous variables, where $\boldsymbol{F}^{\mathbf{- 1}}$ reflects those relations.

Once the reduced form is estimated, one needs to find $\boldsymbol{A}^{\mathbf{- 1}}$ and $\boldsymbol{B}$ to get $\boldsymbol{F}$, given that we want the structural model, which is uncovered by pre-multiplying the reduced form VAR, $X_{t}=E_{1} X_{t-1}+e_{t}$, by $F^{-1}$ namely, $F^{-1} X_{t}=F^{-1} E_{1} X_{t-1}+F^{-1} e_{t}$, where: $F^{-1}=B^{-1} A$.

Substituting $F^{-1}$, the model $F^{-1} X_{t}=F^{-1} E_{1} X_{t-1}+F^{-1} e_{t}$ becomes $B^{-1} A X_{t}=$ $B^{-1} A A^{-1} B G_{1} X_{t-1}+B^{-1} A A^{-1} B u_{t}$. And using $e_{t}=A^{-1} B u_{t}, E_{i}=F G_{i}, F^{-1}=B^{-1} A$ and $\boldsymbol{I}=\boldsymbol{B}^{-\mathbf{1}} \boldsymbol{A} \boldsymbol{A}^{-\mathbf{1}} \boldsymbol{B}$, simplification uncovers the structural shocks and structural coefficients $\boldsymbol{G} \mathrm{s}$, and $\boldsymbol{F}$ s are found: $\boldsymbol{F}^{-1} \boldsymbol{X}_{t}=\boldsymbol{G}_{\mathbf{1}} \boldsymbol{X}_{t-1}+\boldsymbol{u}_{t}$,

In Structural Vector Autoregressive (SVAR) models, there are more unknown coefficients in the structural model than information in the reduced-form VAR estimation. Thus, to uncover the coefficients included in matrices $\boldsymbol{A}, \boldsymbol{B}$ and $\boldsymbol{G}$, it is necessary to impose restrictions on some parameters, which need to make institutional and economic sense.

The assumptions in BP are used: 1) the government does not change spending in response to GDP within the quarter, such that $\boldsymbol{b}_{\mathbf{1}}=\mathbf{0} ; 2$ ) spending decisions are taken before those on taxation, and thus $\boldsymbol{b}_{\mathbf{2}}=\mathbf{0}$ and $\boldsymbol{a}_{\mathbf{2}}$ is estimated. Decisions on taxes are taken first, so $\boldsymbol{a}_{\mathbf{2}}=\mathbf{0}$ and $\boldsymbol{b}_{\mathbf{2}}$ is estimated. BP then estimate $\boldsymbol{a}_{\mathbf{1}}$ outside the system--the effect on tax revenues of GDP's forecast errors. Using regressions for different taxes, BP obtains the elasticity of the tax base to GDP as well as the elasticity of tax collection to the tax base and combine them. 
BP's estimate of this combined elasticity, which is 2 , is used for all countries, although the identification of the shocks is not very sensitive to the size of this constant. ${ }^{3}$

BP also obtained $\boldsymbol{c}_{\mathbf{1}}$ and $\boldsymbol{c}_{\mathbf{2}}$ outside the system, estimating equation (1.3) with instrumental variables. Since causality goes both ways - taxation and GDP affect each other-BP uses the cyclically adjusted, reduced-form tax residual $\boldsymbol{e} \boldsymbol{r}_{\boldsymbol{t}}=\boldsymbol{e}_{\boldsymbol{t}}^{T}-\boldsymbol{a}_{\mathbf{1}} \boldsymbol{e}_{\boldsymbol{t}}^{\boldsymbol{y}}$ as an instrument, and only estimate $\boldsymbol{a}_{2}$ inside the SVAR using MLE to get the impulse responses after a spending shock, or estimate $\boldsymbol{b}_{\mathbf{2}}$ after a tax shock. The reduced-form VAR used by BP to obtain the errors in equations 1.1 to 1.3 included a large set of seasonal dummies to allow for the coefficients at each lag to depend on the particular quarter that indexes the dependent variable. This is because there are seasonal patterns in the response of taxes to economic activity. A tax that is usually paid during the last quarter of the year depends on GDP in the current and the past three quarters, but that tax collection will be zero in the other three quarters, so it does not depend on GDP. Although, to obtain their impulse responses they estimate a VAR without quarter dependence. Hence, they get the average dynamic response to fiscal shocks.

However, this instrumental variable estimation strategy of $\boldsymbol{c}_{\mathbf{1}}$ and $\boldsymbol{c}_{\mathbf{2}}$ is not the only option. Those coefficients can also be estimated using MLE within the SVAR that produces the impulse responses. However, the estimates of $\boldsymbol{c}_{\mathbf{1}}$ and $\boldsymbol{c}_{\mathbf{2}}$ with MLE will differ from the IV estimation because the SVAR used to obtain the impulse responses does not include the dummies that allow for quarter dependence (Ouliaris, Pagan, Restrepo, 2016).

Also, the variance of the structural shocks can be freely estimated with the VAR but then the estimated $\boldsymbol{B}$ matrix should be normalized dividing each of its estimated columns by the standard deviation of the respective structural shock, i.e. dividing each element of that column by the element of such column that is on the diagonal of the estimated $\boldsymbol{B}$ matrix. Thus, the first column is divided by the standard deviation of the first structural shock $\widehat{\boldsymbol{B}}_{\mathbf{1 1}}$, the second column is divided by the standard deviation of the second shock $\widehat{\boldsymbol{B}}_{\mathbf{2 2}}$, and the third column is divided by $\widehat{\boldsymbol{B}}_{\mathbf{3 3}}$. Indeed, $\boldsymbol{c}_{\mathbf{1}}$ and $\boldsymbol{c}_{\mathbf{2}}$ were alternatively obtained here within the SVAR without imposing that the variance of the structural shocks was $1 .^{4}$

BP's timing assumption requires quarterly data on fiscal variables and real output, which reduces the sample of LAC countries to eight: Brazil, Chile, Colombia, Dominican Republic, Mexico, Paraguay, Peru, and Uruguay. The variables used were government revenue net of interest payments and part of the subsidies and transfers; government spending, including expenditures on wages and goods and services plus investment and the remaining part of the transfers; and the country's GDP. To control for the effect of commodity prices and foreign demand on government revenues and spending, the terms-of-trade index and the tradeweighted foreign partners' GDP were included as exogenous variables in the SVARs.

\footnotetext{
${ }^{3}$ This elasticity is assumed to be 1 or slightly larger. A reas onable level for LAC could be between 1 and 2 , since economic growth is as sociated with higher taxation, including through the effects of formalization. For the sake of pragmatismand comparability, the BP estimate of 2 was used for all countries.

${ }^{4}$ In some cases, one of these coefficients, $\boldsymbol{c}_{\mathbf{1}}$ and/or $\boldsymbol{c}_{\mathbf{2}}$, was picked from the respective ins trumental variable estimation if it was statistically significant.
} 
BP define the multiplier as the ratio of the peak (trough) response of GDP to the initial government spending (tax) unit shock. More specifically, BP want to get the multiplier being expressed as dollar for dollar. Thus, the original impulse responses, which are elasticities, given that the variables were estimated in $\operatorname{logs}\left(\frac{\Delta y / y}{\Delta s / s}\right)$, are transformed into dollar for dollar responses $\left(\frac{\Delta Y}{\Delta S}\right)$ by multiplying the former by $\left(\frac{Y}{S}\right)$, which is the average ratio of GDP to government spending. ${ }^{5}$ This paper will also compute the multiplier of Ramey and Zubairy (2018), which is defined as the cumulative response of GDP over the cumulative response of public spending (tax) over two years:

$$
m=\left(\sum_{t=1}^{8} \text { Yresponse }_{t} / \sum_{t=1}^{8} \text { Sresponse }_{t} \text { or } \sum_{t=1}^{8} \text { Yresponse }_{t} / \sum_{t=1}^{8} \text { Tresponse }_{t}\right)
$$

This multiplier is also called the integral multiplier. To get the responses to shocks and, with them, the multipliers, one can compute $\boldsymbol{e}_{t}=\boldsymbol{A}^{-\mathbf{1}} \boldsymbol{B} \boldsymbol{u}_{\boldsymbol{t}}$ or the same $\boldsymbol{e}_{\boldsymbol{t}}=\boldsymbol{F} \boldsymbol{u}_{\boldsymbol{t}}$, where $\boldsymbol{F}$ is computed using $\boldsymbol{A}$ and $\boldsymbol{B}$, since $\boldsymbol{F}=\boldsymbol{A}^{-\mathbf{1}} \boldsymbol{B}$.

Given that Dickey-Fuller tests applied to US data were not conclusive, Blanchard and Perotti estimated two VAR specifications to obtain impulse responses and, with them, the spending and tax multipliers. One includes deterministic linear and quadratic trends, assuming that the variables of the VAR are trend stationary. The second estimation assumes that each variable has a stochastic trend (unit root), but there is no cointegration. Therefore, the first differences of the variables are included in the VAR. They also stated in their paper that they estimated a VEC model, not reported, imposing a cointegrating relation between spending and revenues with very similar results to the benchmark case. Their sample covers from 1960 to 1997. This paper also estimates a SVEC specification imposing BP's restrictions.

\section{Implications of the Definition of Multiplier}

This paper replicates BP's impulse responses for the United States and use them to calculate both BP's definition of multipliers as well as the integral spending and tax multipliers used by Ramey and Zubairy (2018). The results below show that using BP's data and estimation, the cumulative tax multiplier is much larger than the peak one as well as than the cumulative spending multiplier.

Spending shocks. Figure 1 shows the responses to a unit spending shock, when spending decisions come first ( $b_{2}=0$ and $a_{2}$ is estimated). To reproduce BP's estimation, besides tax revenues, government spending and GDP, the VAR includes a quadratic polynomial in time to account for the presence of deterministic trends, seasonal dummies, and dummy variables to account for the temporary tax cut in 1975. The figures show both the replication, in colors, and the original published chart.

As expected, spending shocks have a positive effect on output. According to BP, the peak multiplier is 1.29 , reached in 15 quarters. Thus, one additional dollar of spending increases

\footnotetext{
${ }^{5}$ To get the dollar for dollar res ponse of tax revenues to a spending shock $\left(\frac{\Delta T}{\Delta S}\right)$, the response of taxes $\left(\frac{\Delta t / t}{\Delta s / s}\right)$ should be multiplied by $\left(\frac{T}{s}\right)$. Similar calculations are performed to get the dollar for dollar tax multiplier $\left(\frac{\Delta Y}{\Delta T}\right)$.
} 
GDP by 1.29 dollars. Based on the responses obtained with the replication, the cumulative (integral) multiplier, $m=\frac{\sum_{t=1}^{8} \text { Yresponse }_{t}}{\sum_{t=1}^{8} \text { Sresponse }_{t}}$ is estimated at 0.52 after two years and 0.89 after four years, significantly smaller than the peak multiplier.

\section{Figure 1. US respons es to a spending shock: de terministic tre nds *6}

Response to a Spending Shock
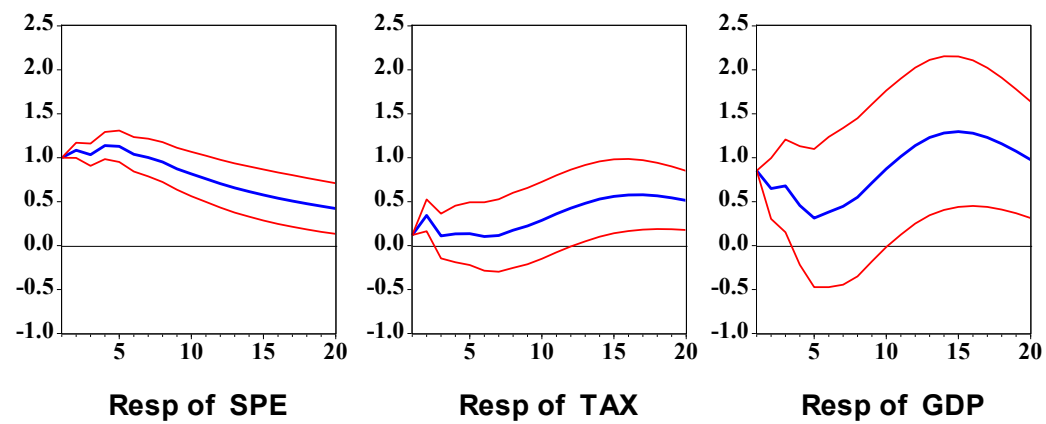

\section{Original Blanchard \& Perotti’s Publis hed Figure}
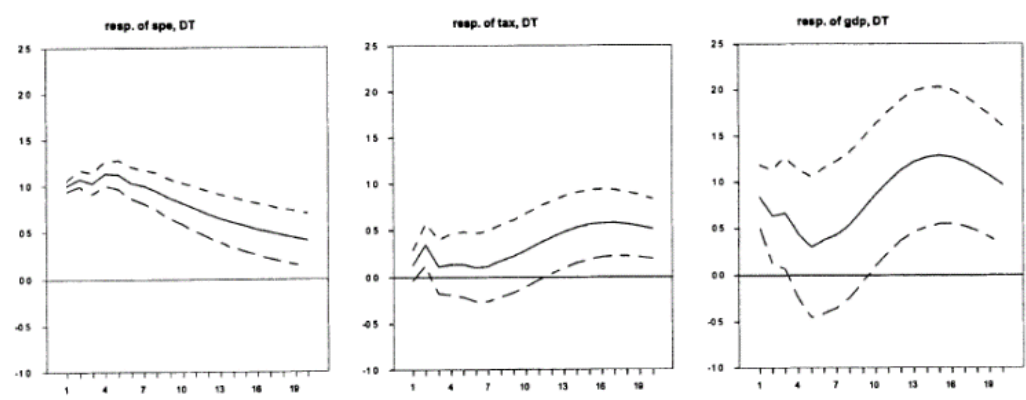

The second BP's VAR specification includes the first differences of the variables, assuming that the variables are not cointegrated. Figure 2 shows the respective impulse responses. BP finds that the peak multiplier is 0.9 , which is reached at impact. Based on the replicated estimation, the cumulative spending multiplier is 0.68 after two years and 0.55 after four years. Again, the cumulative spending multiplier is much smaller than the peak one reported by BP.

\footnotetext{
${ }^{6}$ All responses throughout the paper are dollar for dollar. For instance, a shock to government spending of one dollargenerates 1.29 dollars of GDP reached in 15 quarters (Figure 1), i.e., the vertical axis corres ponds to dollars in all impulse responses and all shocks are one-dollar shocks. Also, all figures show one-standarddeviation confidence intervals.
} 
Figure 2. US: respons es to a spending shock: stochastic trends

Response to a Spending Shock
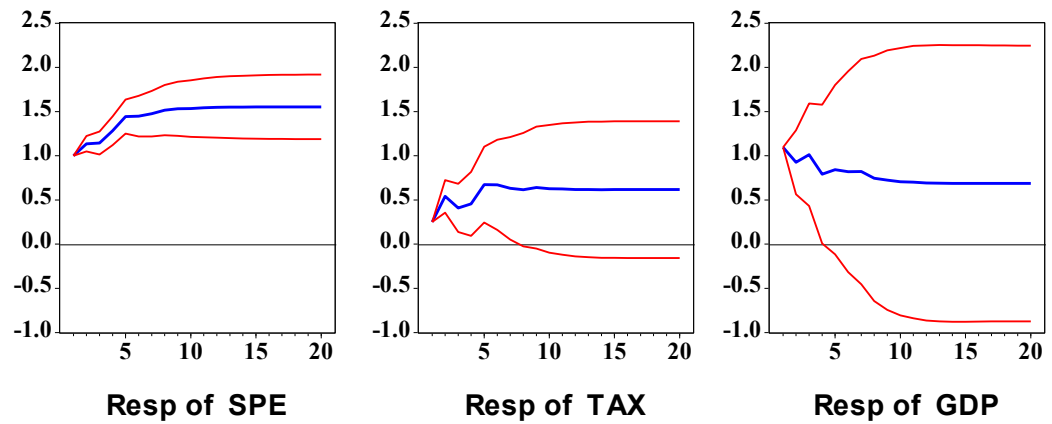

Original Blanchard \& Perotti's Published Figure
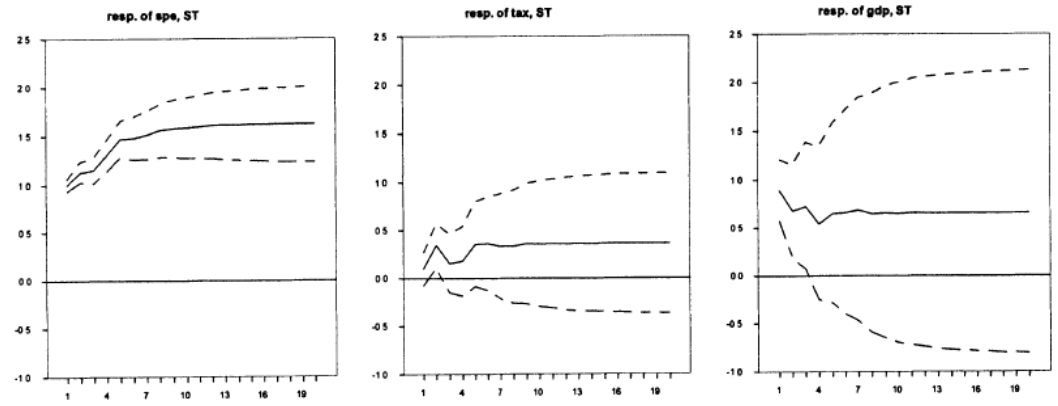

Tax shocks are also identified using BP's data and strategy, i.e., assuming that tax decisions come first ( $a_{2}=0$ and $b_{2}$ is estimated). As before, the first estimation includes deterministic trends while the second uses variables in first differences. Tax hikes have a negative impact on GDP in both specifications. BP finds that the trough multiplier obtained under the deterministic trend specification is -0.78 , which is reached after 5 quarters (Figure 3). Using the replicated results, the cumulative tax multiplier $m \sum_{t=1}^{8}$ Yresponse $_{t} / \sum_{t=1}^{8}$ Tresponse $_{t}$ is computed at -1.9 after 5 quarters and at -4.0 after two years. With the stochastic trend specification, BP reports a trough multiplier of -1.33 seven quarters after the shock, while the cumulative tax multiplier reaches -2.54 after eight quarters. The much-larger cumulative tax multiplier is due to lower persistence of the tax response (denominator) than the spending one. 
Figure 3. US: responses to a tax shock: de terminis tic trends

Response to a Tax Shock
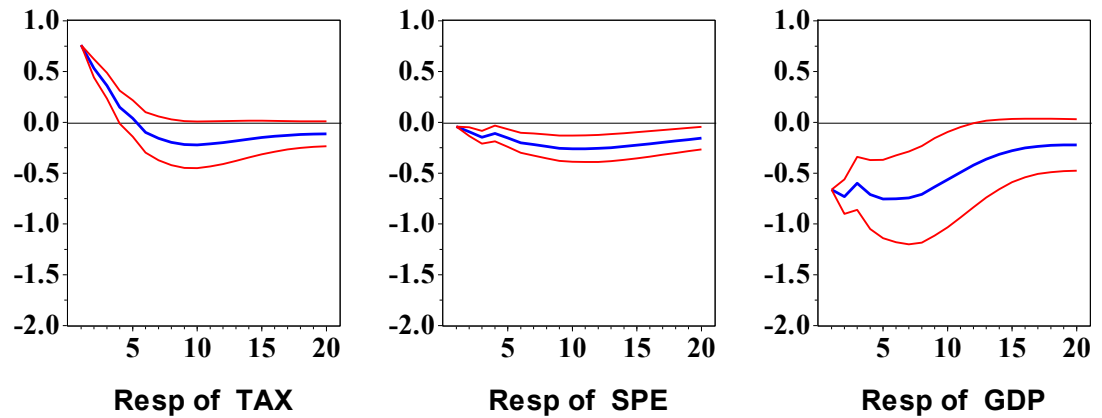

Original Blanchard \& Perotti's Published Figure
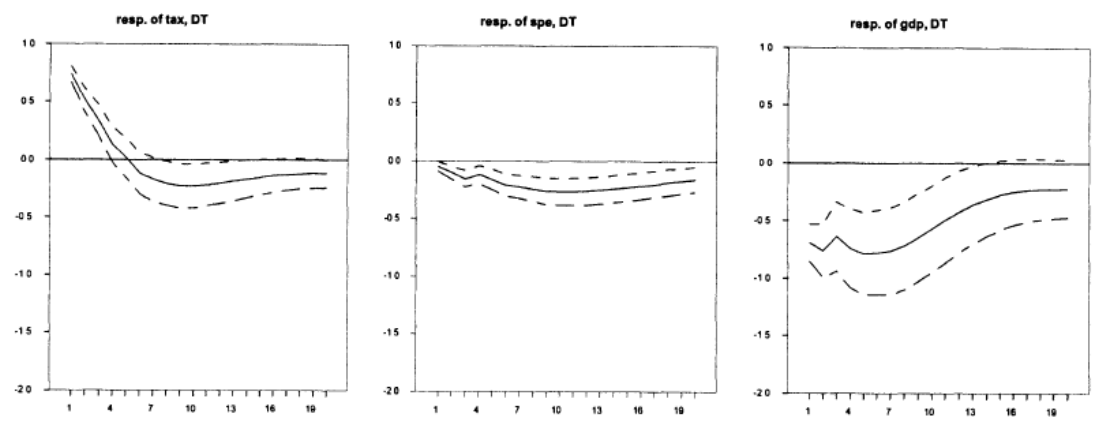

Figure 4. US: responses to a tax shock: s tochastic trends

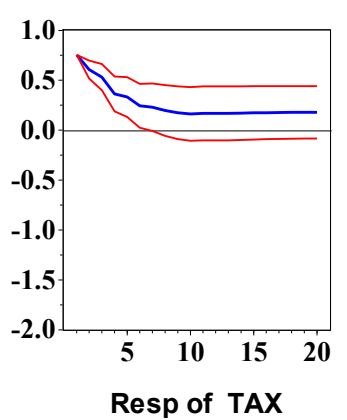

Response to a Tax Shock
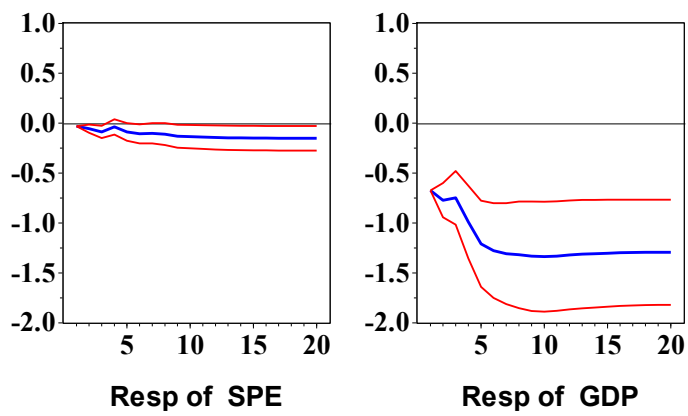

Original Blanchard \& Perotti's Publis hed Figure
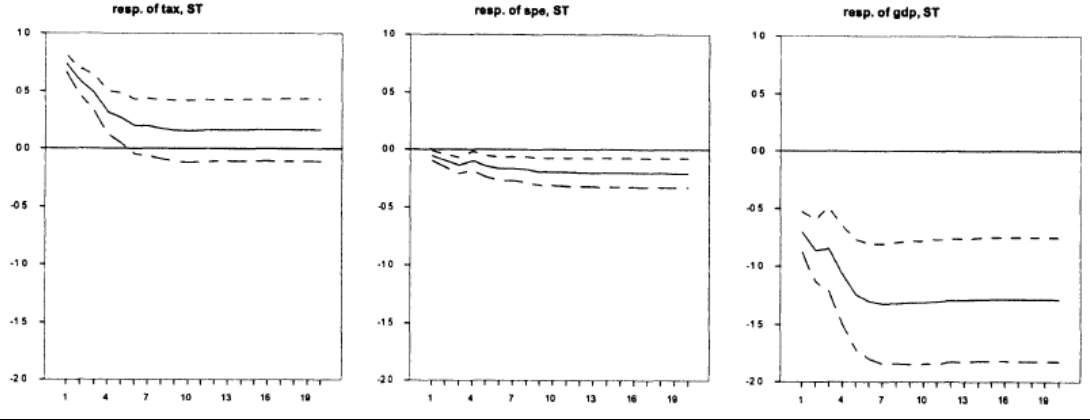
In summary, the cumulative spending multipliers computed as in Ramey and Zubairy (2018) but using with BP's estimated impulse responses are smaller than the point estimates reported by $\mathrm{BP}$, while the cumulative tax multipliers are much larger. Hence, the definition of multiplier matters. BP's definition is in line with the VAR tradition (Sims, 1980), where the responses of the variables are traced after an exogenous shock leads to joint movements of variables. The cumulative multiplier, according to Ramey and Zubairy (2018), may be a better representation when the effects of fiscal policy build over time.

\section{MULTIPLIERS IN LAC COUNTRIES}

This section reports the results obtained for the eight LAC countries. The data coverage and sources for each country are described in table 1. Dickey-Fuller test were performed for all country series (Table 2) and in most cases it is not possible to reject the unit root hypothesis. However, the results about cointegration between Spending (SS) and tax revenues (TT) are not conclusive with few exceptions.

A SVAR (or SVEC) is estimated, including spending, tax revenues and GDP [ss, tt, yy], all in real per capita terms. Since the goal is to identify exogenous shocks to public spending or taxes, the analysis controls for the country's terms of trade and trading partners' growth, which are included in the VAR as exogenous variables. Movements in revenues or spending that are consequence of these exogenous variables are excluded from the set of exogenous spending and tax shocks. The SVAR-SVEC estimated here did not include any deterministic trend, but rather estimates the system in first differences. ${ }^{7}$ As in BP, the variables included in the VAR are the same for both spending or revenue shocks.

\begin{tabular}{|c|c|c|c|}
\hline \multicolumn{4}{|c|}{ Table 1. Data, Sources, and Coverage } \\
\hline & Series coverage & Sample & Source \\
\hline BRA & Central Government & 1997:1 - 2017:2 & Haver \\
\hline CHL & Central Government & 1990:1 - 2017:2 & Authorities, IFS, Haver \\
\hline COL & Central Government & $1995: 1-2017: 2$ & Authorities, Haver \\
\hline DOM & Central Government & 1991:1 - 2017:2 & CentralBank \\
\hline MEX & Central Government & 1990:1 - 2017:2 & Authorities, Haver \\
\hline PER & Central Government & 2003:1 - 2017:2 & Authorities, Haver \\
\hline PAR & Central Government & 2003:1 - 2017:2 & Authorities, Haver \\
\hline URU & Central Government & $2005: 2-2017: 2$ & Authorities, Haver \\
\hline USA & General Government & 1960:1 - 1997:4 & $\begin{array}{l}* \text { http://econ- } \\
\text { www.mit.edu/files/722 }\end{array}$ \\
\hline
\end{tabular}

${ }^{7}$ The Dickey-Fuller test results point to the exis tence of stochastic trends and cointegration in Paraguay. 


\section{Low frequency properties}

Augmented Dickey-Fuller tests were performed to analyze the low frequency properties of the series used to estimate the multipliers. In the overwhelming majority of cases, it was not possible to reject the null hypothesis of the existence of a unit root (Table 2). Therefore, stationary SVARs with the variables in first differences were estimated. In addition, if the variables are cointegrated, structural vector error correction (SVEC) models were used to estimate the multipliers instead of SVARs. ${ }^{8}$

The unit root tests point to possible cointegration between taxes and spending in Chile, Colombia and Paraguay. In fact, unit root tests on the difference between tax collection, TT, and government spending, SS, show that it is stationary hinting that there is a long-run relation between these two variables. To obtain the multipliers for those countries, the analysis imposes a long-run cointegration restriction between the tax and the spending variables and estimates structural vector error correction models (SVEC), using the BP's short-run identification strategy. If there is cointegration, a SVAR in first differences would not be correctly specified -the error correction term would be missing. Thus, I would give more weight to the results obtained with the SVEC estimation, if having also the SVAR one.

\begin{tabular}{|c|c|c|c|c|c|c|c|c|}
\hline \multicolumn{9}{|c|}{ Table 2. Dickey-Fuller Tests } \\
\hline & \multirow{3}{*}{ SS } & \multirow{3}{*}{ TT } & \multirow{3}{*}{ YY } & \multirow{3}{*}{ TT- SS } & \multicolumn{4}{|c|}{ Critical values } \\
\hline & & & & & \multicolumn{2}{|c|}{ No trend } & \multicolumn{2}{|c|}{ Trend } \\
\hline & & & & & $1 \%$ & $5 \%$ & $1 \%$ & $5 \%$ \\
\hline Brazil & $-2,81(1, \mathrm{t})$ & $-1.25(5)$ & $-1.12(1)$ & $-1.60(1)^{9}$ & -3.52 & -2.90 & -4.08 & -3.47 \\
\hline Chile & $-2.26(8, \mathrm{t})$ & $-2.94(9, \mathrm{t})$ & $-2.13(9, \mathrm{t})$ & $-4.13(9, t)$ & -3.50 & -2.89 & -4.05 & -3.45 \\
\hline Colombia & $-3.19(1, \mathrm{t})$ & $-4.82(1, t)$ & $-2.31(2, \mathrm{t})$ & $-8.21(0, t)$ & -3.51 & -2.90 & -4.07 & -3.46 \\
\hline Dom Rep & $-2.09(12, \mathrm{t})$ & $-2.40(8, \mathrm{t})$ & $-2.13(12, \mathrm{t})$ & $-2.07(8)$ & -3.50 & -2.89 & -4.06 & -3.46 \\
\hline Mexico & $-1.97(9, \mathrm{t})$ & $-2.97(7, \mathrm{t})$ & $-3.05(5, \mathrm{t})$ & $-1.91(4)$ & -3.50 & -2.89 & -4.05 & -3.46 \\
\hline Paraguay & $-3.46(0, \mathrm{t})$ & $-2.04(3, \mathrm{t})$ & $-3.61(8, t)$ & $-3.78(4, t)$ & -3.55 & -2.91 & -4.13 & -3.49 \\
\hline Peru & $-2.93(1, \mathrm{t})$ & $-2.04(0, t)$ & $-1.61(4)$ & $-2.49(1, \mathrm{t})$ & -3.56 & -2.92 & -4.13 & -3.49 \\
\hline Uruguay & $-3.40(3, \mathrm{t})$ & $-3.13(3, \mathrm{t})$ & $-3.05(5, \mathrm{t})$ & $-1.76(1)$ & -3.53 & -2.90 & -4.08 & -3.47 \\
\hline$\overline{\text { USA }}$ & $-2.71(3)$ & $-3.22(0, \mathrm{t})$ & $-2.85(2, \mathrm{t})$ & $-2.99(2)$ & -3.47 & -2.88 & -4.02 & -3.44 \\
\hline \multicolumn{9}{|c|}{$\begin{array}{l}\text { T statistic. The number of lags used appears in parenthesis and a } t \text { if a trend was included in the test. } \\
\text { Whenever autocorraltion was detected in the residuals, more lags were included guarantee that they were } \\
\text { white noise. } \\
\text { T-S would be stationary in Brazil if we restrict the sample to end in } 2014.4 \text { when the fiscal situation } \\
\text { started deteriorating substantially. }\end{array}$} \\
\hline
\end{tabular}

\section{Results}

\footnotetext{
${ }^{8}$ Whenever the variables have a unit root and, at the same time, they are not cointegrated, I estimate the system in first differences (no determinis tic trends). Otherwise, the relation among trending variables in levels could be spurious. If the variables are cointegrated, I es timate vector error correction models instead, given that a SVAR in first differences would notbe correctly specified as above said. It is worth adding that, not here but in the literature, cointegrated systems are alternatively estimated in levels.
} 
Table 3 presents the multipliers estimated with SVARs, with the variables in first differences, and, in some cases, SVEC models. The multipliers were computed using the point estimates of the impulse responses. Table 3 includes both the peak, or trough, multipliers using the BP identification strategy for every country and the eight-quarter cumulative multipliers, defined as $\left(m=\frac{\sum_{t=1}^{8} \text { Yresponse }_{t}}{\sum_{t=1}^{8} \text { Sresponse }_{t}}\right.$ or $\left.\frac{\sum_{t=1}^{8} \text { Yresponse }_{t}}{\sum_{t=1}^{8} \text { Tresponse }_{t}}\right)$. The number of lags was chosen to guarantee that there is no autocorrelation in the residuals ${ }^{10}$. In any economy, the size of the multipliers could depend on many factors like the level of income, degree of openness, size of the government, level of debt, composition of spending and taxes, business cycle. The analysis of the differences in the size of the multipliers I found is beyond the scope of this paper.

\begin{tabular}{|c|c|c|c|c|c|c|c|c|c|c|}
\hline & \multicolumn{5}{|c|}{ SPENDING } & \multicolumn{5}{|c|}{ TAX } \\
\hline & \multicolumn{2}{|c|}{\begin{tabular}{|l} 
Peak \\
\end{tabular}} & & \multicolumn{2}{|c|}{ Cumulative } & \multicolumn{2}{|c|}{ Peak } & & \multicolumn{2}{|c|}{ Cumulative } \\
\hline & SVAR & SVEC & Quarter & SVAR & SVEC & \begin{tabular}{|l} 
SVAR \\
\end{tabular} & SVEC & Quarter & SVAR & SVEC \\
\hline BRA: 4 & 0.59 & & 4 & 0.81 & & -0.31 & & 1 & -0.44 & \\
\hline CHL: 4 & 1.71 & 1.12 & $3-2$ & 1.19 & 0.42 & -0.24 & -0.48 & $1-1$ & -0.25 & -0.49 \\
\hline COL: 4 & 1.01 & 0.99 & $9-12$ & 1.89 & 1.56 & -0.75 & -0.68 & $8-1$ & -3.03 & -1.34 \\
\hline DOM: 2 & 0.40 & & 3 & 0.47 & & -0.48 & & 1 & -0.38 & \\
\hline MEX: 4 & 0.40 & & 2 & 0.72 & & -0.29 & & 5 & -0.36 & \\
\hline PER: 5 & 0.75 & & 6 & 1.14 & & -0.74 & & 6 & -1.46 & \\
\hline PAR: 3 & 0.95 & 0.98 & $5-1$ & 1.15 & 0.63 & -1.51 & -1.37 & $4-1$ & -3.80 & -3.14 \\
\hline URU: 2 & 0.41 & & 1 & 0.53 & & -0.71 & & 5 & -2.88 & \\
\hline USA: 4 & 1.10 & & 1 & 0.68 & & -1.34 & & 10 & -2.54 & \\
\hline
\end{tabular}

In Brazil, the cumulative multipliers are larger than the peak/through multipliers. The peak multiplier for government spending is 0.59 , reached after four quarters, while the cumulative multiplier is 0.81 after two years (Table 3 and Figure 5). The trough tax multiplier is 0.31 , reached on impact, while the cumulative multiplier is 0.44 after two years. Matheson and Pereira (2016) estimated multipliers for Brazil using a VAR with a different identification strategy. They found a similar peak multiplier for government spending (slightly above 0.5 ) and a somewhat larger through tax multiplier (slightly below 0.5 ).

In Chile, based on the low frequency properties (Table 2), a SVEC estimation is called for. However, I still estimated both a SVAR and a SVEC. The peak multiplier of a spending shock is 1.71 after three quarters with a SVAR and 1.12 after two quarters with a SVEC, while the cumulative multiplier after two years is 1.19 with a SVAR and only 0.42 with a

\footnotetext{
${ }^{10}$ Akaike, Schwarz, Hannan-Quinn are commonly used criteria to select the number of lags. Each one penalizes differently the use of lags. However, what really matters is to have the (minimum) number of lags that produce white noise residuals, and that is what I did here. Note that using quarterly data it is common to have 4 lags.
} 
SVEC due to the persistence of government spending (Table 3 and Figure 6). On tax shocks, the SVAR through multiplier is -0.24 reached on impact and the cumulative one is -0.25 after two years. The SVEC through multiplier is -0.48 also reached on impact, and the cummulative one -0.49 . Other studies have found larger multipliers. Fornero and others (2019) find a cumulative multiplier of 2 for a combined shock to government consumption and investment, while Cespedes and others (2012) find a peak consumption and investment multiplier of 1.27 , reached after a year, while the 8 -quarter cumulative multiplier is $2.8 .{ }^{11}$

\section{Figure 5. Brazil: responses to a spending and tax shocks}

Response to a Spending Shock
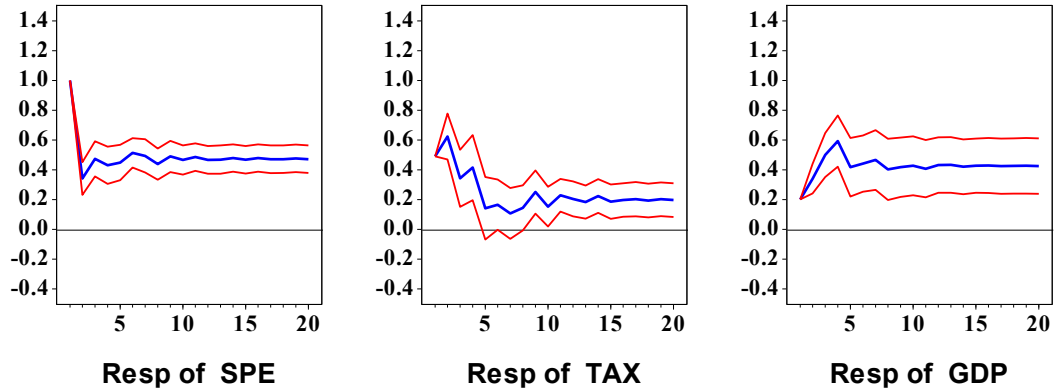

Brazil: Response to a Tax Shock
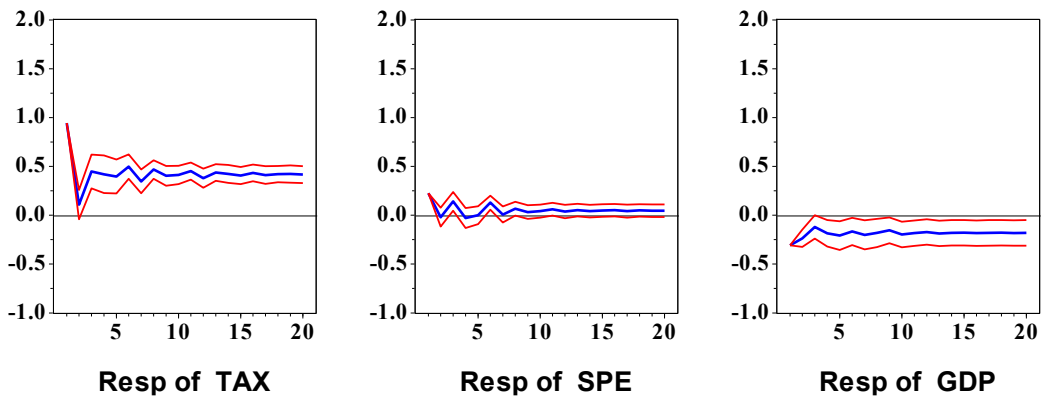

The estimated multipliers for Colombia are among the largest in the sample although they are somewhat smaller when a SVEC is estimated (Table 3 and Figure 7). ${ }^{12}$ The cumulative multipliers are much larger than the peak (or trough) ones. With the SVAR, the peak spending multiplier is 1.01 after nine quarters, while the cumulative multiplier is 1.9. Based on the SVEC, the peak multiplier is 0.99 after 12 quarters, while the cummulative multiplier is 1.6. Regarding the impact of tax shocks, the SVAR trough multiplier is 0.75 , while the two-year cumulative multiplier is -3 . The SVEC trough multiplier is 0.68 , with a cummulative multiplier of -1.3 after two years. ${ }^{13}$

\footnotetext{
${ }^{11}$ Restrepo and Rincón(2006), using a different sample, find a peak spending multiplier of 1.9 for Chile, which stabilizes at 1.35, but it is only significant in the first two-to-three quarters. The taxmultiplier is smaller at 0.4. ${ }^{12}$ Previous estimates of fiscal multipliers for Colombia can be found in Restrepo and Rincón (2006), although for a different definition of government.

${ }^{13}$ These results are compatible with the multipliers of Lopez-Vera and others (2018) after two years: Spending shock 0.64 (boom) and 0.99 (recession); taxshock -0.71 (boom) and -1.12 (recession).
} 
Figure 6. Chile: respons es to a spending and tax shocks

Response to a Spending Shock
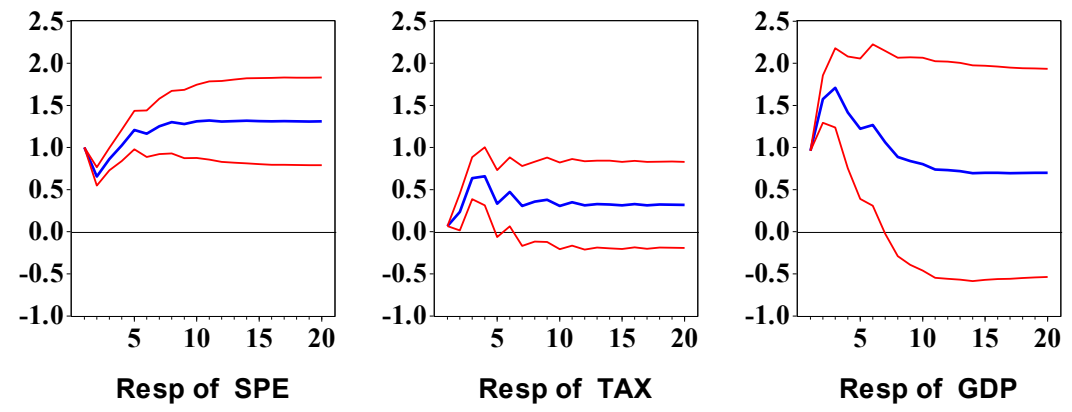

Chile: Response to a Spending Shock (SVEC\&Bootstrap)
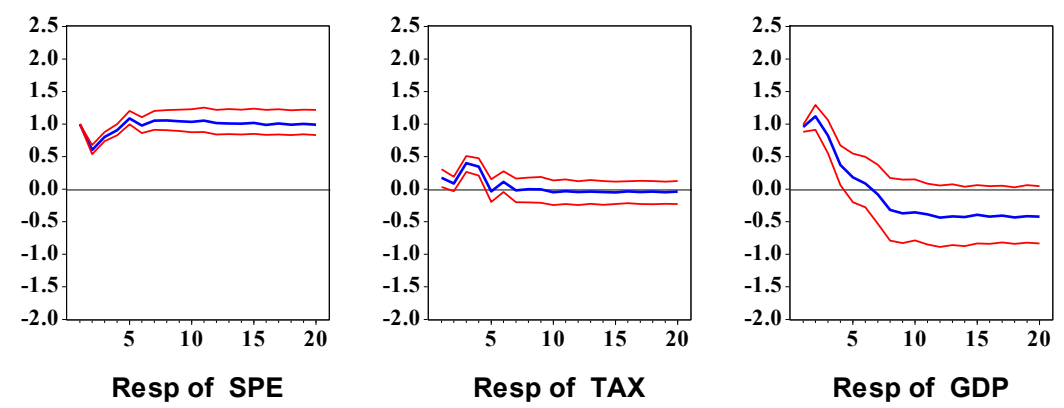

Chile: Response to a Tax Shock
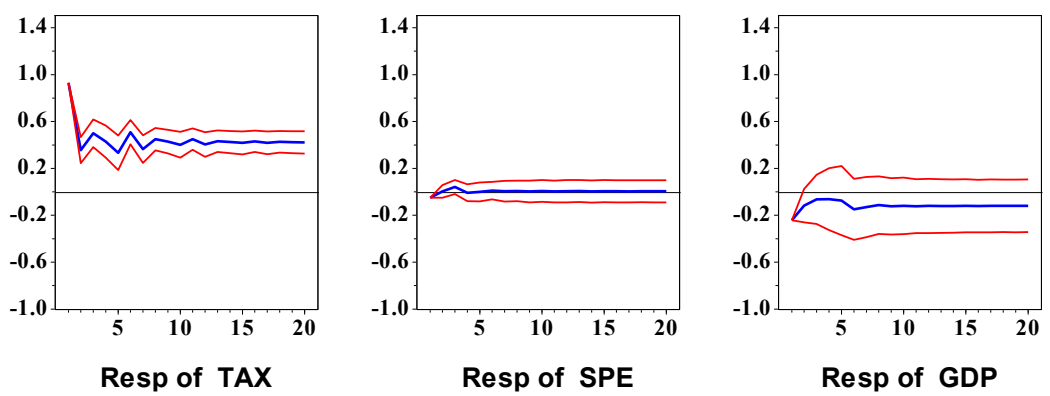

Chile:Response to a Tax Shock (SVEC\&Bootstrap)
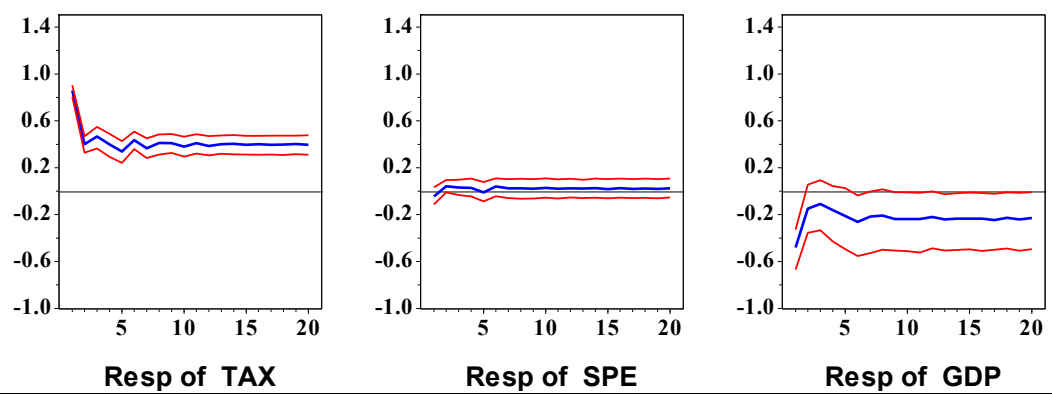

CInternational Monetary Fund. Not for Redistribution 
Figure 7. Colombia: responses to a spending and tax shocks

Colombia: Response to a Spending Shock
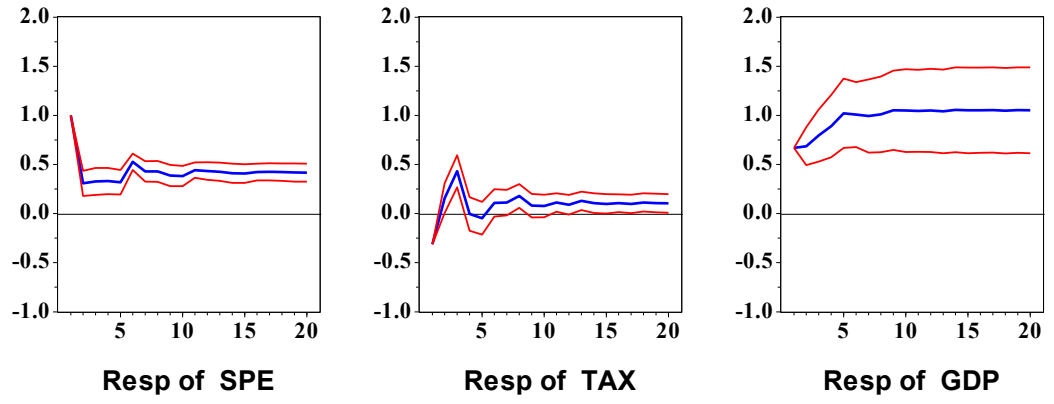

Colombia:Response to a Spending Shock (SVEC\&Bootstrap)
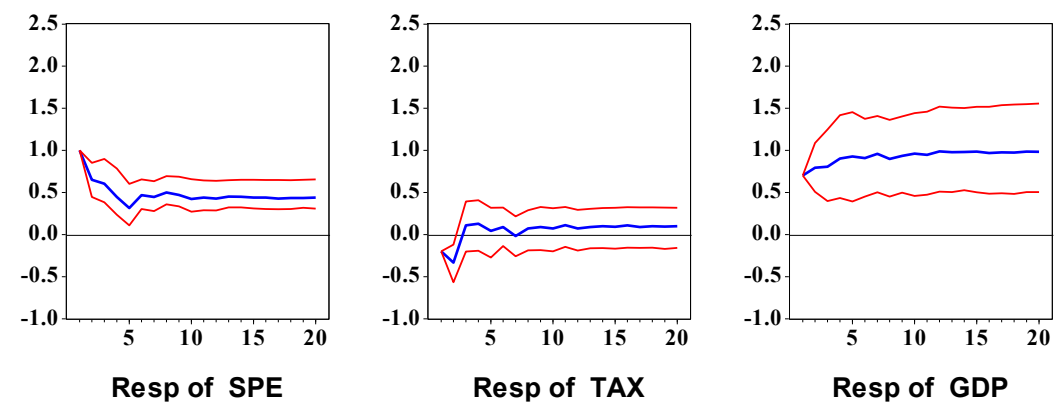

Colombia: Response to a Tax Shock
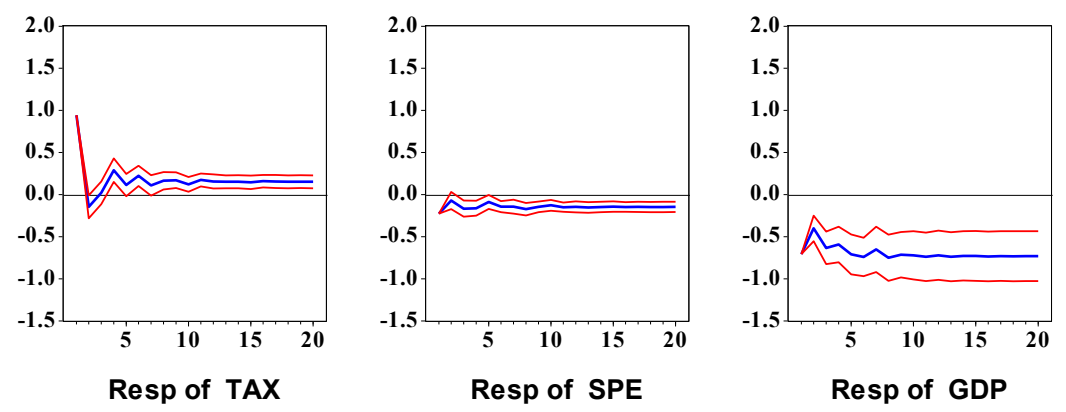

Colombia:Response to a Tax Shock (SVEC\&Bootstrap)
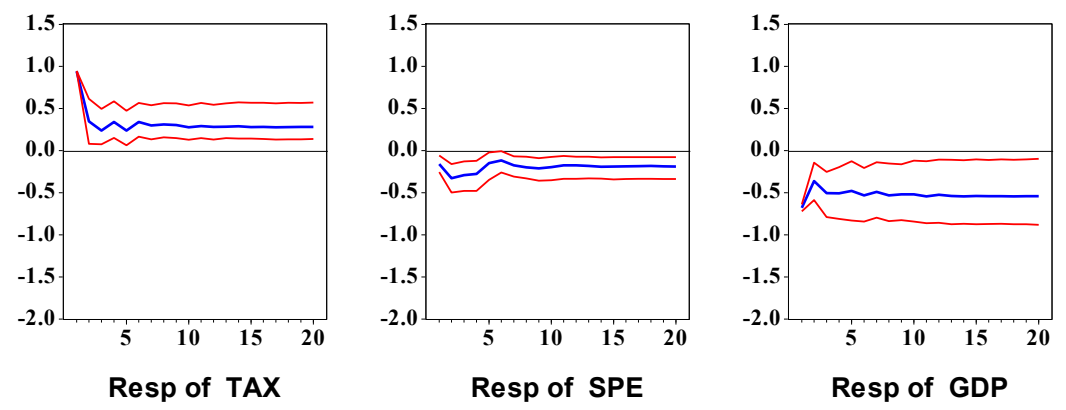
In the Dominican Republic, the peak spending multiplier is estimated at 0.40 after three quarters, and the cumulative multiplier at 0.47 after two years (Table 3 and Figure 8). The trough tax multiplier is estimated at -0.48 , reached on impact, and the cumulative multiplier at $-0.38 .{ }^{14}$ These multipliers are larger than those estimated with a six-variable SVEC model by Estevao and Samake (2013), but are similar to those in the International Monetary Fund (IMF), 2018.

\section{Figure 8. Dominican Republic: res pons es to a spending and tax shocks}

Response to a Spending Shock
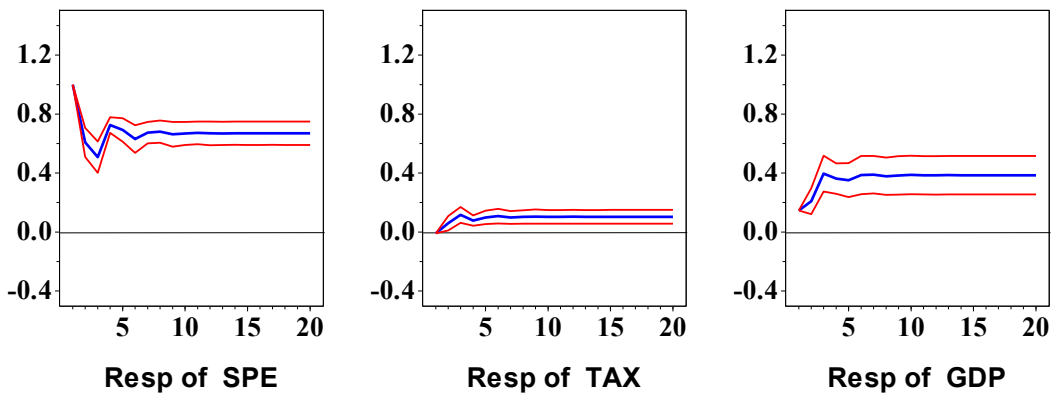

Dom. Rep.: Response to a Tax Shock
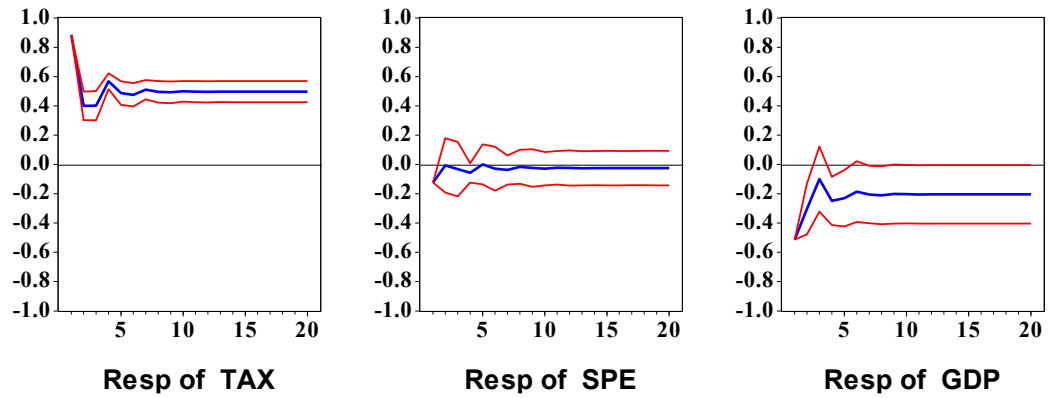

In Mexico, the peak spending multiplier is estimated at 0.40 after two quarters, and the twoyear cumulative multiplier at 0.72 (Table 3 and Figure 9). These values are in line with the multipliers estimated by Valencia (2015) using state-level spending in Mexico. On the other hand, the trough tax multiplier is estimated at -0.29 after five quarters, while the cumulative tax multiplier is estimated at -0.36 .

${ }^{14}$ The revenuedata excludes that related to Petro Caribe's debt, which was forgiven in 2015. 
Figure 9. Mexico: responses to a spending and tax shocks

Mexico: Response to a Spending Shock
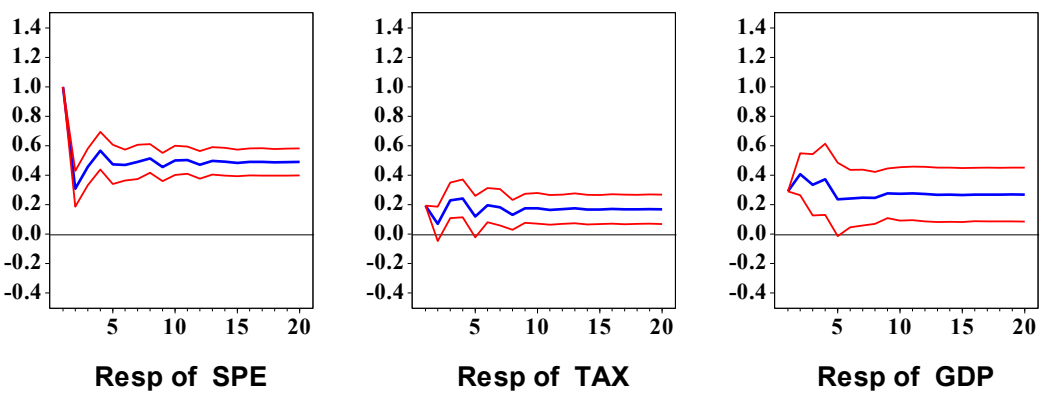

Mexico: Response to a Tax Shock
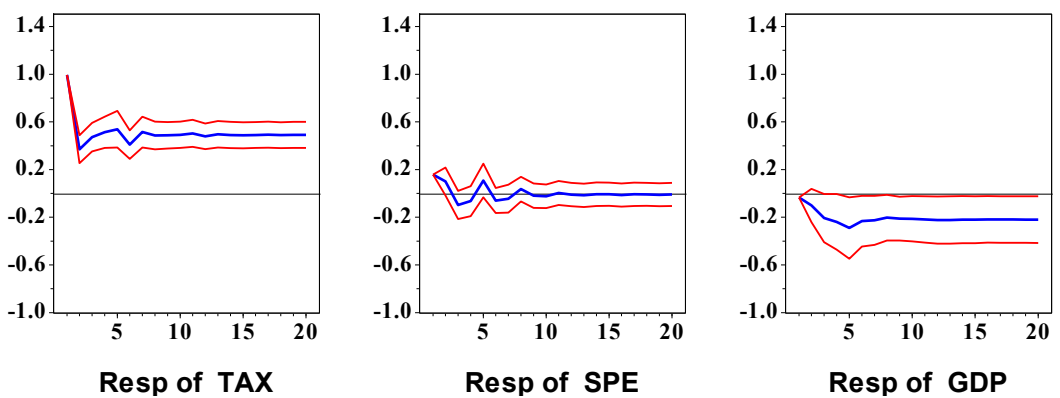

The estimated multipliers for Paraguay are among the largest (Table 3 and Figure 10). Using a SVAR, the peak spending multiplier is 0.95 after five quarters, while the cumulative multiplier is 1.15. Using a SVEC, the peak spending multiplier is estimated at 0.98 and the cumulative multiplier at 0.63 . For taxes, the SVAR estimates the trough tax multiplier at 1.51 after four quarters and the cumulative multiplier at -3.80 . The SVEC estimates the trough tax multiplier at -1.37 on impact and a cummulative multiplier of -3.14 . These results imply a negative "balanced budget multiplier," as the tax multiplier is larger in absolute terms than the spending multiplier. These results contrast with those in David (2017), which finds a positive balanced budget multiplier using diferent techniques to identify fiscal shocks, including VARs, the local projection method, and the narrative approach. The VARs used in David (2017) are different for the estimation of spending and tax multipliers and are also different from the ones used here in terms of variables included as well as the sample. 
Figure 10. Paraguay: SVAR and SVEC responses to a spending and tax shocks

Paraguay: Response to a Spending Shock
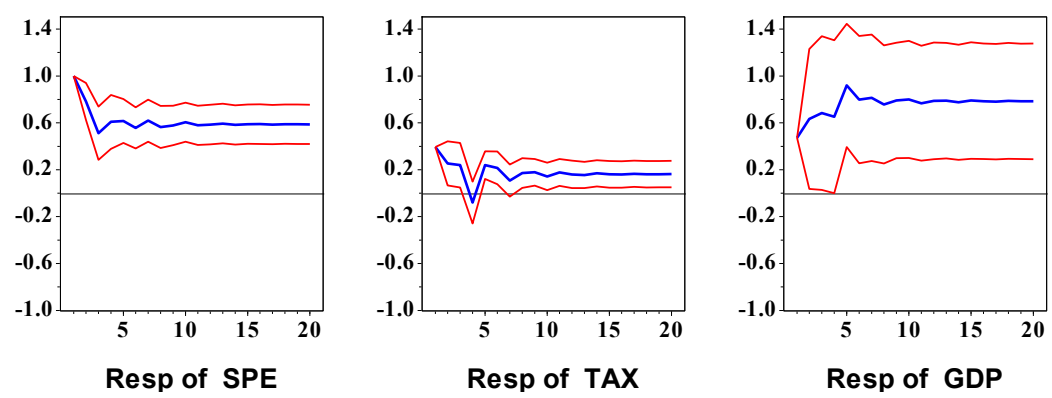

Paraguay: Response to a Tax Shock
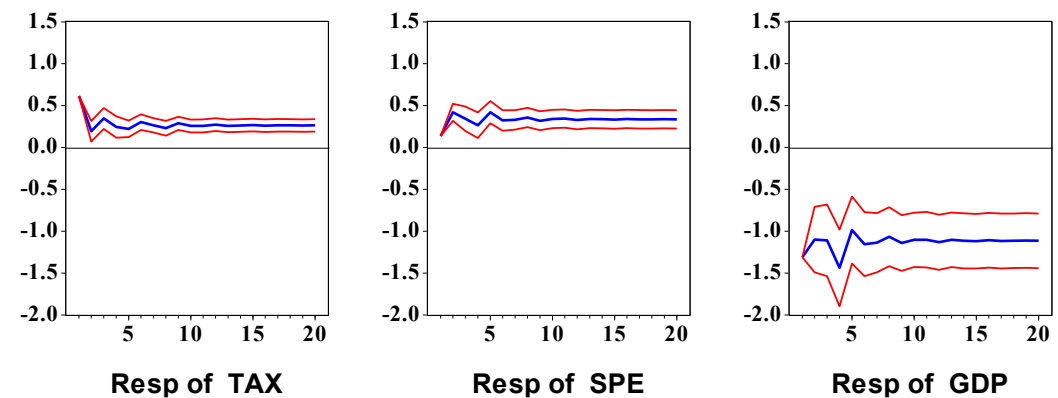

Paraguay: Response to a Spending Shock (SVEC\&Bootstrap)
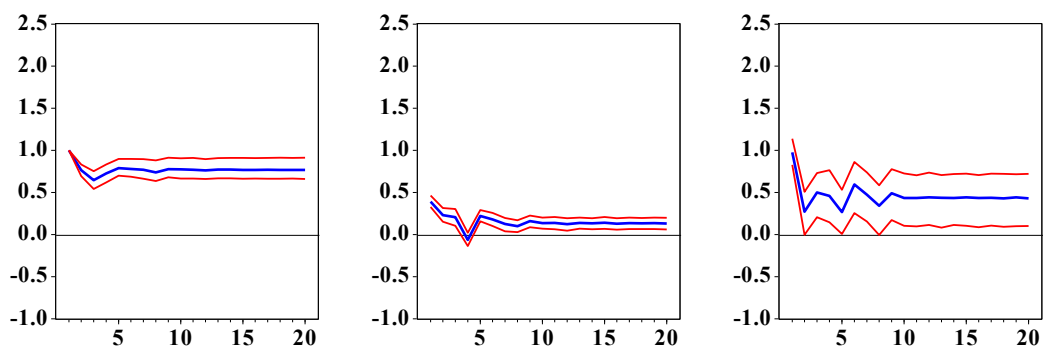

Resp of SPE

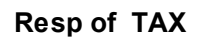

Resp of GDP

Paraguay: Response to a Tax Shock (SVEC\&Bootstrap)
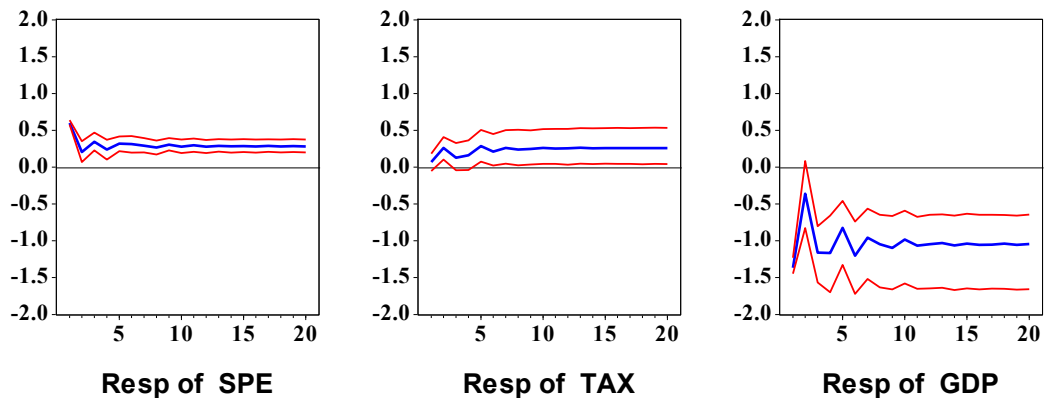

CInternational Monetary Fund. Not for Redistribution 
In Peru, the peak spending multiplier is estimated at 0.75 after six quarters, and the two-year cumulative multiplier at 1.14 (Table 3 and Figure 11). The trough tax multiplier is estimated at -0.74 after six quarters, and the cumulative multiplier at -1.46 . These multipliers are larger than those in Vtyurina and Leal (2016), which estimate cumulative multipliers for capital spending during downturns at 0.5 after four quarters, rising to 1.1 after 12 quarters. However, the multipliers estimated here are closer to those estimated by the Central Reserve Bank of Peru in 2012 and the Ministry of Economy and Finance in 2015.

\section{Figure 11. Peru: responses to a spending and tax shocks}

Peru: Response to a Spending Shock
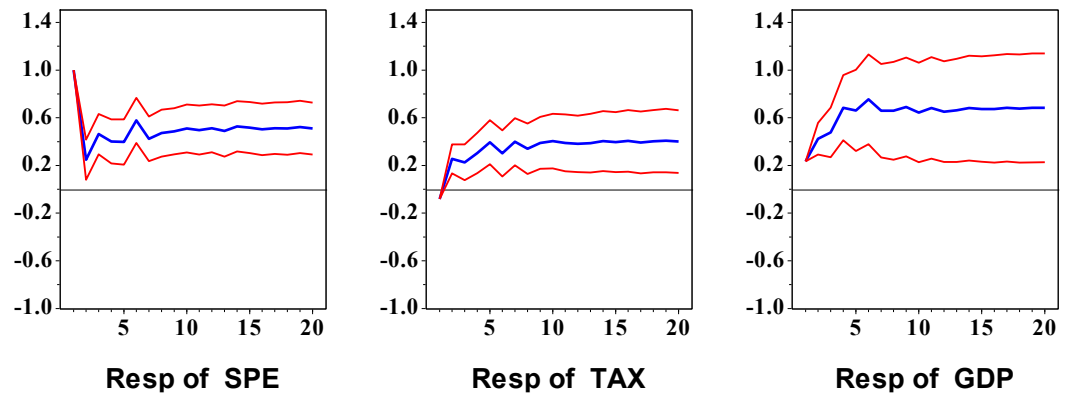

Peru: Response to a Tax Shock
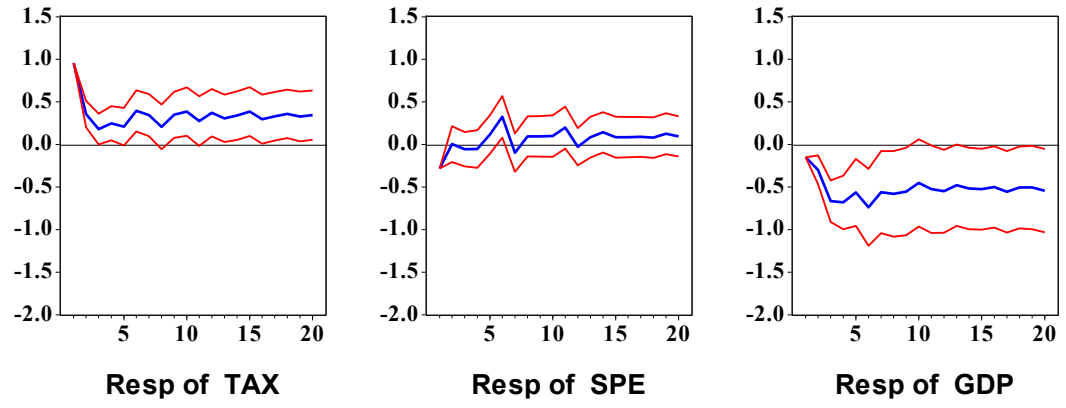

In Uruguay, the peak spending multiplier is estimated at 0.41 after two quarters and the twoyear cumulative multiplier at 0.53 (Table 3 and Figure 12). The trough tax multiplier, on the other hand, is estimated at -0.71 after five quarters, and the cumulative multiplier at -2.88 as the tax response after the shock vanishes quickly while the GDP effect persists. 
Figure 12. Uruguay: responses to a spending and tax shocks

Uruguay: Response to a Spending Shock
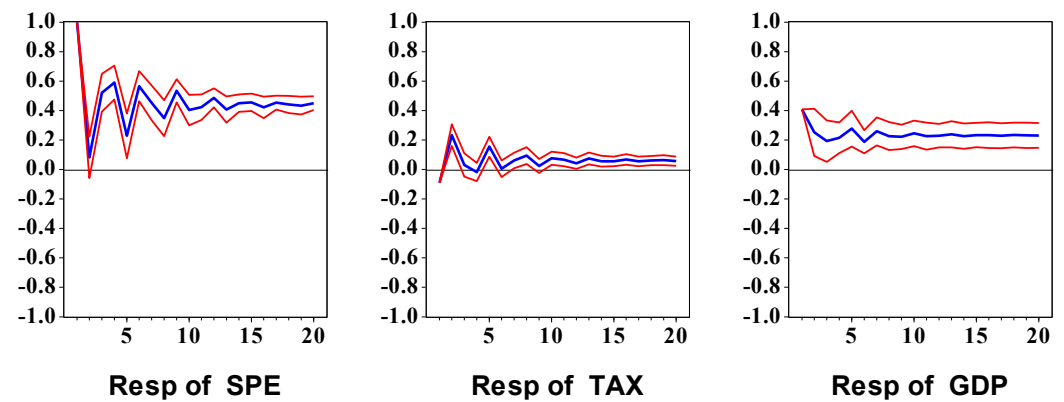

Uruguay: Response to a Tax Shock
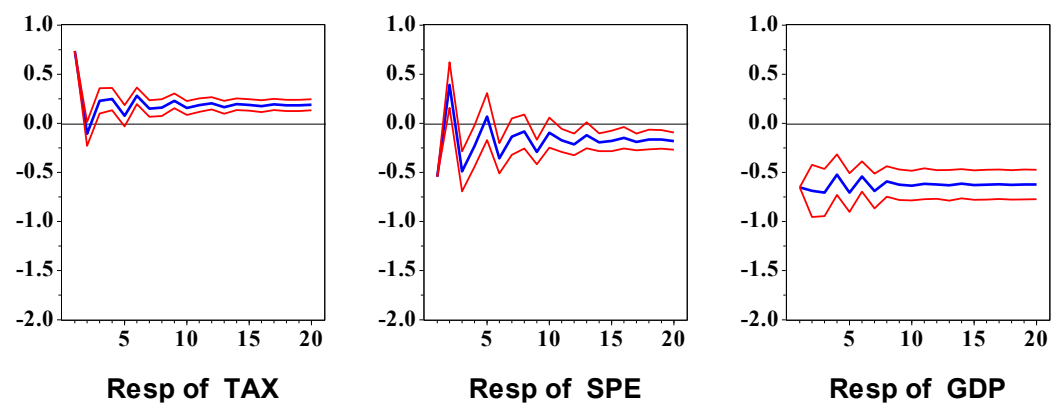

\section{SumMARY AND CONCLUS IONS}

The expansionary policies put in place during the 2009 global financial crisis and, later on, the fall of commodity prices left public finances in bad shape in many LAC economies, with large fiscal deficits and debt following an unsustainable path. As a result, several countries in LAC are now consolidating their fiscal accounts and will continue to do so in the coming years. In this context, it is important to know the likely impact of fiscal consolidation on economic activity, and to have good estimates of fiscal multipliers.

This paper replicates the approach of Blanchard and Perotti (2002) for the United States and applies it to estimate fiscal multipliers for eight LAC economies. SVARs in differences and in some cases SVECs are estimated. Two definitions of multipliers are used: 1) the peak spending or trough tax multipliers of Blanchard and Perotti; and 2) the two-year cumulative multiplier (two -year cumulated response of GDP to the two-year cumulated response of government spending or tax revenues) as in Ramey and Zubairy (2018).

The two-year cumulative multipliers for spending are often smaller than the peak ones, while the cumulative tax multipliers are larger than the through multipliers in several cases. For the United States, the results of Blanchard and Perotti (2002) imply a much larger cummulative tax multiplier (-2.54) than the cummulative spending multiplier (0.68). For LAC, the results suggest that the impact of fiscal shocks on GDP varies significantly across countries. The size of the multiplier could help design a better fiscal policy for instance regarding the speed and timing of a fiscal consolidation. 


\section{References}

Blanchard O. and R. Perotti, 2002, "An Empirical Characterization of the Dynamic Effects of Changes in Government Spending and Taxes on Output." QJE, November 1329-68.

Carriere-Swalow, Y., A. David and D. Leigh, 2018, "The Macroeconomic Effects of Fiscal Consolidation in Emerging Economies: Evidence from Latin America." IMF Working Paper WP/18/142 (Washington: International Monetary Fund).

Central Reserve Bank of Peru, 2012, "Inflation Report: Recent Trends and Macroeconomic Forecasts 2012-14" (June).

Céspedes, L.F., J. Fornero y J. Galí, 2012, "Non-Ricardian Aspects of Fiscal Policy in Chile." En Fiscal Policy and Macroeconomic Performance, editado por L.F. Céspedes y J. Galí, serie Banca Central, Análisis y Políticas Económicas, vol. 17, Banco Central

David, A., 2017, "Fiscal Policy Effectiveness in a Small Open Economy: Estimates of Tax and Spending Multipliers in Paraguay." IMF Working Paper WP/17/63 (Washington: International Monetary Fund).

Estevao, M. and I. Samake, 2013, "The Economic Effects of Fiscal Consolidation with Debt Feedback." IMF Working Paper WP/13/136 (Washington: International Monetary Fund).

Fornero, J., J. Guerra-Salas, and C. Pérez, 2019, "Multiplicadores fiscales en Chile." Revista de Economia Chilena, Central Bank of Chile, 22: 58-80.

Ilzetzki E., E. Mendoza and C. Vegh, 2011, "How Big (Small?) Are Fiscal Multipliers?" International Monetary Fund WP/11/52.

IMF Western Hemisphere Department Regional Economic Outlook, 2018, Chapter 4. "Fiscal Multipliers: How Will Consolidation Affect Latin America and the Caribbean?"

(Washington: International Monetary Fund).

International Monetary Fund (IMF), 2018, "Poverty, inequality and redistribution in the Dominican Republic," in Dominican Republic 2018 Article IV Consultation-Selected Issues, IMF Country Report No. 18/294 (Washington).

López-Vera, A., A. Pinchao-Rosero, and N. Rodríguez-Niñoa, 2018, "Non-Linear Fiscal Multipliers for Public Expenditure and Tax Revenue in Colombia." Ensayos de política económica vol.36 no. 85. Banco de la República de Colombia.

Matheson, T. and Pereira, J., 2016, "Fiscal Multipliers for Brazil" IMF Working Paper WP/16/79 (Washington: International Monetary Fund).

Ministry of Economy and Finance of Peru, 2015, "Multiannual Macroeconomic Framework," 2016-18. Ministry of Finance of Peru, April. 
Ouliaris, S. A. Pagan, and J. Restrepo, 2018, Quantitative Macroeconomic Modeling with Structural Vector Autoregressions - An EViews Implementation.

https://www.eviews.com/StructVAR/structvar.html

Ramey, V. S. Zubairi, 2018, “Government Spending Multipliers in Good Times and in Bad: Evidence from US Historical Data.” JPE 126, no. 2 (April 2018): 850-901.

Restrepo, J. and H. Rincón, 2006, "Identifying fiscal shocks in Chile and Colombia." Central Bank of Chile, Working Paper 360.

Valencia, F., 2015, "Fiscal Multipliers in Mexico." IMF Country Report No. 15/314 Selected Issues Papers.

Vtyurina, S. and Z. Leal, 2016, "Fiscal Multipliers and Institutions in Peru: Getting the Largest Bang for the Sol” IMF WP/16/144.

World Bank, 2018, "Fiscal Adjustment in Latin America and the Caribbean: Short-run pain, long-run gain?" Semiannual Report Office of the Regional Chief Economist April. 